\title{
The Investigation According to Some Variables of COVID-19 Fear Levels of High School Students in the Pandemic Process
}

\author{
Sitk1 Özbek (Corresponding author) \\ Milli Eğitim Bakanlığg, Kırşehir, Turkey \\ E-mail: zsonike@gmail.com.tr
}

\author{
Hüseyin Nasip Özaltaş \\ Dicle Üniversitesi Beden Eğitimi ve Spor Yüksekokulu, Diyarbakır, Turkey \\ E-mail: huseyinozaltas@gmail.com
}

Received: November 5, 2021 Accepted: December 2, 2021

Published: December 31, 2021

doi:10.5296/jei.v7i3.19185 URL: https://doi.org/10.5296/jei.v7i3.19185

\begin{abstract}
The aim of this study was to examine the COVID-19 fear of high school students in the COVID-19 pandemic proccess, based on a few characteristics. Within the scope of this aim, the study's research group; in the 2020-2021 academic year, a total of 760 students, 382 girls and 378 boys, were identified using a sample technique that can be readily located among high school students who continue their studies in Krşehir province. In the research, for determining the COVID-19 fear levels of students, Ahorsu et al. (2020), and Bakioğlu et al. (2020) "COVID-19 Fear Scale" adapted into Turkish was used. Kolmogorov-Smirnowa values showed that the data were normally distributed. Frequency and percentage analyzes were applied in descriptive statistics, $T$ test was used in the analysis of binary groups, and One way Anova was used in the analysis of three or more groups. As a result of these analyzes, it was determined that the high school students participating in the study had a moderate $(\overline{\mathrm{x}}=15.7)$ fear of COVID-19. It was determined that the COVID-19 fear levels of high school students the pandemic process, according to the gender variable, the COVID-19 fears of female students $(\overline{\mathrm{x}}=17.26)$ were significantly higher than male students $(\overline{\mathrm{x}}=14.21)$. Yet, it was determined that the variables of age, class, being in the school team, doing licensed sports, type of sports, duration of doing sports and getting COVID-19 disease did not have a significant effect on
\end{abstract}


high school students' fear of COVID-19. As a conclusion, it was shown that fear of COVID-19 in high school students created substantial disparities in favor of girls only on the basis of gender. Other characteristics revealed in the study had no significant effect on high school students' COVID-19 fear levels.

Keywords: Fear of COVID-19, Pandemic, High school students

\section{Introduction}

Coronavirus illness (COVID-19) is a pulmonary ailment caused by a new coronavirus that first occurred in Wuhan, China in December 2019 (Lai et al., 2020). According to WHO data on 22 June 2021, COVID-19 illness, which has been designated a pandemic by the World Health Organization (WHO), has infected more than 178 million individuals globally and killed more than 3.5 million people (WHO, 2020). In our country, it has been announced that more than 5 million people are infected and the number of cases that have died is over 49.000 (WHO, 2021). However, the number of new cases and deaths reported is increasing gradually.

Precautions to be taken to control the disease; it is known as filiation of infected individuals and providing isolation (Aktuğ et al., 2020). In many countries of the world, including Turkey, temporary curfews and physical distance rules are applied (WHO, 2020).

COVID-19 has deeply impacted the entire sports community as well as the whole world. The sudden cessation of sports, the postponement and cancellation of the competitions negatively affected the athletes psychologically, sociologically and spiritually. In the COVID-19 process, the inability of the athletes to train, the fear of losing their performance, boredom, anxiety, fear, anxiety, extreme nervous sensitivity, stress and emotional confusion also affected the aggression levels of the athletes (Şahinler et al., 2020).

The deaths reasoned by COVID-19, the environment of uncertainty, the lack of a definitive treatment, its rapid spread, widespread information pollution, compulsory changes in daily life habits, acute psychiatric symptoms developing in infected people and difficulties associated with reaching a physician make the pandemic to be handled spiritually. This makes the cure process mandatory (Brown et al., 2020).

To treat COVID-19, scientists around the world focused on the diagnostic and therapeutic aspects of the disease. On the other hand, there is limited number of studies on the subject. Psychological effects of COVID-19 on mental health (Mamun \& Griffiths, 2020; Pakpour \& Griffiths, 2020; Schimmenti et al., 2020; Wang et al., 2020). The outbreak of COVID-19 and its pandemic nature have caused widespread anxiety, fear and anxiety (Ahorsu et al., 2020). COVID-19 triggers fear among individuals, making it important to understand the impact of the crisis on people's mental health (Xiang, 2020).

Assesment tools were needed to reveal the effects of COVID-19 on mental health. Regarding this emerging need, Ahorsu et al. (2020) developed a valid and reliable scale to assess fear of COVID-19. The Turkish adaptation of this developed scale was done by Bakioğlu et al. (2020). In this study, our aim is to compare the COVID-19 fear levels of high school students with and 
without a sports background (not doing sports) before the pandemic, according to some variances.

\section{Method}

The study's purpose was to see if there was a significant difference in the COVID-19 fear levels of high school students to the pandemic process, based on several characteristics. In this frame, the research is a relational screening model. In this approach, which is based on researching and describing a past or present situation as it is, the event, phenomenon or situation that is the subject of the research is tried to be explained as it is (Karasar, 2015).

\subsection{Study Group}

The study group of the research consists of a total of 760 participants, 382 women and 378 men, determined by the sampling method that can be easily found among the high school students studying in the province of Kırşehir in the 2020-2021 academic year.

\subsection{Data Collection Tools}

In order to determine the COVID-19 fear levels of students as a data collection tool; the "COVID-19 Fear Scale" developed by Ahorsu et al. (2020) was adapted into Turkish by Bakioğlu et al. (2020) used in the research.

\subsection{COVID-19 Fear Scale}

COVID-19 Fear Scale: developed Ahorsu et al. (2020) and adapted into Turkish by Bakioğlu et al. (2020), this scale is a likert-type scale developed to measure the level of COVID-19 fear levels of individuals. It consists of one dimension and 7 items. There is no reverse item in the scale. The total score obtained from all items of the scale reflects the level of fear of Coronavirus (COVID-19) experienced by the individual. The scores that can be obtained from the scale range from 7 to 35 . A high score from the scale means experiencing a high level of fear of coronavirus. The Cronbach alpha internal consistency coefficient was determined as .88. In this study, the Cronbach alpha internal consistency coefficient was found to be .92 .

\subsection{Analysis of Data}

The data acquired in the research were analyzed using the SPSS 22.0 package program. Kolmogorov-Smirnow test was used to test whether the data showed normal distribution, after it was determined that the data were normally distributed, students' gender, did you take part in school teams before the pandemic, did you play licensed sports before the pandemic, did you get COVID-19 disease, independent sample was used for the variables. In the test; age, class, pre-pandemic sport type and pre-pandemic sport duration variables were analyzed with One-Way ANOVA (One-Way Analysis of Variance). 


\section{Findings}

Table 1. Frequency and percentage distributions of students' demographic characteristics

\begin{tabular}{|c|c|c|c|}
\hline Variable & Groups & $\mathbf{N}$ & $\%$ \\
\hline \multirow{3}{*}{ Gender } & Female & 382 & 50.3 \\
\hline & Male & 378 & 49.7 \\
\hline & Total & 760 & 100 \\
\hline \multirow{6}{*}{ Age } & 14 Years old and below & 32 & 4.2 \\
\hline & 15 Years old & 226 & 29.7 \\
\hline & 16 Years old & 222 & 29.2 \\
\hline & 17 Years old & 244 & 32.1 \\
\hline & 18 Years old and above & 36 & 4.7 \\
\hline & Total & 760 & 100 \\
\hline \multirow{5}{*}{ Grade } & 1. & 244 & 32.1 \\
\hline & 2. & 212 & 27.9 \\
\hline & 3. & 226 & 29.7 \\
\hline & 4 & 78 & 10.3 \\
\hline & Total & 760 & 100 \\
\hline \multirow{3}{*}{$\begin{array}{l}\text { Have you ever taken part in school teams } \\
\text { before pandemic? }\end{array}$} & Yes & 300 & 39.5 \\
\hline & No & 460 & 60.5 \\
\hline & Total & 760 & 100 \\
\hline \multirow{3}{*}{$\begin{array}{l}\text { Have you ever done sports as licensed } \\
\text { before the pandemic? }\end{array}$} & Yes & 290 & 38.2 \\
\hline & No & 470 & 61.8 \\
\hline & Total & 760 & 100 \\
\hline \multirow{4}{*}{$\begin{array}{l}\text { What kind of sports have you done } \\
\text { before the pandemic? }\end{array}$} & Individual Sports & 100 & 13.2 \\
\hline & Teams Sports & 238 & 31.3 \\
\hline & I did not do sports & 422 & 55.5 \\
\hline & Total & 760 & 100 \\
\hline \multirow{6}{*}{$\begin{array}{l}\text { What was your period of active sports } \\
\text { before the pandemic? }\end{array}$} & 1-2 Years & 490 & 64.5 \\
\hline & 3-4 Years & 148 & 19.5 \\
\hline & 5-6 Years & 66 & 8.7 \\
\hline & 7-8 Years & 34 & 4.5 \\
\hline & 9 Years and above & 22 & 2.9 \\
\hline & Total & 760 & 100 \\
\hline \multirow{3}{*}{ Have you ever been caught COVID-19 disease? } & Yes & 136 & 17.9 \\
\hline & No & 624 & 82.1 \\
\hline & Total & 760 & 100 \\
\hline
\end{tabular}


When Table 1 is examined, according to the gender variable, $49.7 \%(n=378)$ of the students are male and $50.3 \%(n=382)$ are female. According to the age variable, $4.2 \%(n=32)$ of the students participating in the study were 14 years old and under, $29.7 \%(\mathrm{n}=226)$ were 15 years old, 29.2\% $(\mathrm{n}=222)$ were 16 years old, $32.1 \%(\mathrm{n}=244)$ were 17 years old, $4.7 \%(\mathrm{n}=36)$ were 18 years or older. According to the class variable, $32.1 \%(\mathrm{n}=244)$ of the students were $1 \mathrm{st}$ grade, $27.9 \%(n=212) 2 n d$ grade, $29.7 \%(n=226) 3$ rd grade, $\% 10.3(n=78)$ of them are studying as 4 th grade students. Before the pandemic, $39.5 \%(n=300)$ of the students took part in the school teams, while $60.5 \%(\mathrm{n}=460)$ were not in the school teams. Before the pandemic, $38.2 \%(n=290)$ of the students did sports under license, and $61.8 \%(n=470)$ did not do sports under license. According to the type of sport the students did before the pandemic, $13.2 \%(\mathrm{n}=$ $100)$ did individual sports, $31.3 \%(\mathrm{n}=238)$ did team sports, $55.5 \%(\mathrm{n}=422)$ did the pandemic. $\mathrm{He} / \mathrm{She}$ have not done any sports before. Before the pandemic, according to the variable of duration of active sports, $64.5 \%(\mathrm{n}=490)$ did sports for $1-2$ years, $19.5 \%(\mathrm{n}=148)$ did sports for 3-4 years, $8.7 \%$ Six of them $(n=66)$ did sports for 5-6 years, $4.5 \%(n=34)$ did sports for $7-8$ years, $2.9 \%(n=22)$ did sports for 9 years or more. According to the situation of contracting the COVID-19 disease during the pandemic process, $17.9 \%(\mathrm{n}=136)$ of the students got the disease, and $82.1 \%(n=624)$ have not been caught to an illness.

Table 2. The Average Scores Of The Participants Took From the COVID-19 Fear Scale

\begin{tabular}{|l|l|l|l|}
\hline Scale & $\mathbf{n}$ & $\overline{\mathbf{x}}$ & Ss \\
\hline COVID-19 Fear Scale & 760 & 15.7 & 7.17 \\
\hline
\end{tabular}

When Table 2 is examined, the average score the students got from the fear of COVID-19 scale is $\bar{x}=15.7 \pm 7.17$. With this score obtained from the scale, which can be scored in the range of $7-35$, it was seen that the participant group had "moderate" COVID-19 fears.

Table 3. Normality distribution results of the participants' data on the COVID-19 Fear Scale

\begin{tabular}{|l|l|l|l|l|l|l|}
\hline \multirow{2}{*}{ Scale } & \multicolumn{5}{|c|}{ Kolmogorov-Smirnov $^{\mathbf{a}}$} \\
\cline { 2 - 8 } & Statistic & df & Sig. & $\bar{x}$ & Median & Std. Deviation \\
\hline COVID-19 Fear Scale & .111 & 760 & .000 & 15.74 & 14.00 & 7.17 \\
\hline
\end{tabular}

Since the number of participants was over 50 to examine the distribution of the data in Table 3 , it was determined that the distribution of the data was not normal as a result of the Kolmagrov Smirnova analysis, which is one of the normal distribution analyses $(\mathrm{p}<0.05)$. However, when the other assumptions of the normal distribution, the closeness of the mean-media and the requirement that the kurtosis skewness values be in the range of \pm 1.5 , the Q-Q Plot curve and 


\section{Macrothink}

Histogram graphs are examined; According to the variables, it was determined that these values also fit the normal distribution. According to the central limit theorem, a sample size above 30 indicates that the distribution is close to normal. Since the sample size is 760 , it can be concluded that although the distribution is not normal, it does not deviate from the normal distribution according to the central limit theorem. In the light of this information, it was determined that the data did not diverge too far from the normal distribution, and it was considered to use normal distribution analyzes for the study.

In Table 4, the t-test results regarding the significant difference in the fears of COVID-19 according to the gender of the students are given.

Table 4. T-Test results on the significant difference in students' fear of COVID-19 by gender

\begin{tabular}{|c|c|c|c|c|c|c|c|c|c|}
\hline & \multirow{2}{*}{ Gender } & \multirow{2}{*}{$\mathbf{n}$} & \multirow{2}{*}{$\overline{\mathbf{x}}$} & \multirow{2}{*}{ Sd } & \multirow{2}{*}{ df } & \multicolumn{2}{|c|}{ Levene Test } & \multirow{2}{*}{$\mathbf{T}$} & \multirow{2}{*}{$\mathbf{P}$} \\
\hline & & & & & & $\mathbf{F}$ & $\mathbf{p}$ & & \\
\hline \multirow{2}{*}{ COVID-19 Fear Scale } & Girl & 382 & 17.26 & 6.87 & \multirow{2}{*}{758} & \multirow{2}{*}{0.11} & \multirow{2}{*}{0.74} & \multirow{2}{*}{5.99} & \multirow{2}{*}{$.00^{* *}$} \\
\hline & Boy & 378 & 14.21 & 7.14 & & & & & \\
\hline
\end{tabular}

When Table 4 is examined; As a result of examining whether there is a significant difference in the fear of COVID-19 according to the gender of the students, it was determined that there was a significant difference $(p>0.05)$ in the mean scores of the fear of COVID-19 according to the gender. When the significant difference was examined from which group, it was concluded that the mean scores obtained from the fear of COVID-19 scale were significantly different in favor of female students. In other words, it was determined that female $(\bar{x}=17.26)$ students' fear of COVID-19 was significantly higher than male $(\overline{\mathrm{x}}=14.21)$ students.

In Table 5, the t-test results regarding the significant difference in the fears of COVID-19 according to the status of the students in the school teams before the pandemic are presented. 


\section{Macrothink}

Table 5. T-Test results on the significant difference in fears of COVID-19 according to the status of students in school teams before the pandemic

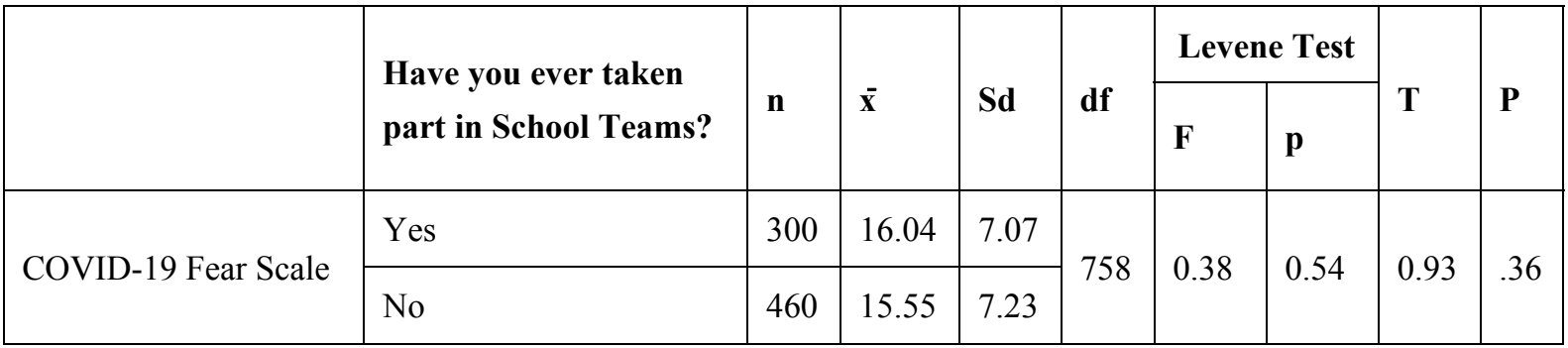

When Table 5 is examined; As a result of examining whether there was a significant difference in COVID-19 fears according to the status of students in school teams before the pandemic, it was determined that the status of being in school teams before the pandemic did not create a significant difference $(p>0.05)$ in the mean scores of COVID-19 fears.

In Table 6, the t-test results regarding the significant difference in the fears of COVID-19 according to the licensed sports status of the students before the pandemic are given.

Table 6. T-Test results of the significant difference in fear of COVID-19 according to students' licensed sports before the pandemic

\begin{tabular}{|c|c|c|c|c|c|c|c|c|c|}
\hline & \multirow{2}{*}{$\begin{array}{l}\text { Have you ever done } \\
\text { sports as Licenced? }\end{array}$} & \multirow{2}{*}{$\mathbf{n}$} & \multirow{2}{*}{$\overline{\mathbf{x}}$} & \multirow{2}{*}{ Sd } & \multirow{2}{*}{ df } & \multicolumn{2}{|c|}{ Levene Test } & \multirow{2}{*}{$\mathbf{T}$} & \multirow{2}{*}{$\mathbf{P}$} \\
\hline & & & & & & $\mathbf{F}$ & $\mathbf{p}$ & & \\
\hline \multirow{2}{*}{ COVID-19 Fear Scale } & Yes & 290 & 15.31 & 6.64 & \multirow{2}{*}{758} & \multirow{2}{*}{6.65} & \multirow{2}{*}{0.01} & \multirow{2}{*}{-1.30} & \multirow{2}{*}{.18} \\
\hline & No & 470 & 16.01 & 7.47 & & & & & \\
\hline
\end{tabular}

When Table 6 is examined; As a result of examining whether there is a significant difference in COVID-19 fears according to the licensed sports status of the students before the pandemic, it was determined that the licensed sports status of the students before the pandemic did not create a significant difference $(p>0.05)$ in the mean scores of the COVID-19 fears.

In Table 7, the t-test results of the significant difference in the fears of COVID-19 according to the students' status of contracting the COVID-19 disease are given. 


\section{Macrothink}

Table 7. T-Test results of the significant difference in fear of COVID-19 according to students' situation of being caught to COVID-19 disease

\begin{tabular}{|c|c|c|c|c|c|c|c|c|c|}
\hline & \multirow{2}{*}{$\begin{array}{l}\text { Have you ever been caught } \\
\text { to COVID-19 Disease? }\end{array}$} & \multirow{2}{*}{$\mathbf{n}$} & \multirow{2}{*}{$\overline{\mathbf{x}}$} & \multirow{2}{*}{ Sd } & \multirow{2}{*}{ df } & \multicolumn{2}{|c|}{ Levene Test } & \multirow{2}{*}{$\mathbf{T}$} & \multirow[b]{2}{*}{$\mathbf{P}$} \\
\hline & & & & & & $\mathbf{F}$ & p & & \\
\hline \multirow{2}{*}{ COVID-19 Fear Scale } & Yes & 136 & 15.88 & 8.30 & \multirow{2}{*}{758} & \multirow{2}{*}{9.81} & \multirow{2}{*}{0.00} & \multirow{2}{*}{0.25} & \\
\hline & No & 624 & 15.71 & 6.90 & & & & & \\
\hline
\end{tabular}

When Table 7 is examined; As a result of examining whether there is a significant difference in the COVID-19 fears according to the COVID-19 disease status of the students, it was determined that the COVID-19 disease status of the students did not create a significant difference $(p>0.05)$ in the mean scores of the COVID-19 fears.

Table 8 includes One-Way ANOVA Results regarding the difference in COVID-19 fears according to the age variable of the students.

Table 8. One-Way ANOVA results on the difference in students' fear of COVID-19 depending on age variable

\begin{tabular}{|c|c|c|c|c|c|c|c|c|c|}
\hline \multirow{2}{*}{ Scale } & \multirow{2}{*}{ Age } & \multirow{2}{*}{$\mathbf{N}$} & \multirow{2}{*}{$\overline{\mathbf{x}}$} & \multirow{2}{*}{ Sd } & \multicolumn{2}{|c|}{ Levene Test } & \multirow{2}{*}{$\mathbf{F}$} & \multirow{2}{*}{$\mathbf{p}$} & \multirow{2}{*}{ Scheffe } \\
\hline & & & & & Statistic & $\mathbf{P}$ & & & \\
\hline \multirow{5}{*}{ COVID-19 Fear Scale } & 14 Years old and Below $^{(1)}$ & 32 & 14.06 & 7.23 & \multirow{5}{*}{0.90} & \multirow{5}{*}{0.46} & \multirow{5}{*}{0.65} & \multirow{5}{*}{.63} & \multirow{5}{*}{ - } \\
\hline & 15 Years old $^{(2)}$ & 226 & 15.60 & 6.96 & & & & & \\
\hline & 16 Years old $^{(3)}$ & 222 & 15.68 & 6.82 & & & & & \\
\hline & 17 Years old $^{(4)}$ & 244 & 16.13 & 7.44 & & & & & \\
\hline & 18 Years old and Above ${ }^{(5)}$ & 36 & 15.89 & 8.60 & & & & & \\
\hline
\end{tabular}

When Table 8 is examined; As a result of examining whether there is a significant difference in the mean scores of COVID-19 fears according to the age variable of the students, there is a significant difference in the mean scores of the COVID-19 fears according to the age variable $(p>0.05)$. Because of the homogeneous distribution of group variances, Scheffe test, one of the Post-Hoc tests, was applied.

In Table 9, One-Way ANOVA Results regarding the difference in COVID-19 fears according to the class variable of the students are given. 


\section{Macrothink}

Table 9. One-Way ANOVA results on the difference in students' fear of COVID-19 depending on class variable

\begin{tabular}{|c|c|c|c|c|c|c|c|c|c|}
\hline \multirow{2}{*}{ Scale } & \multirow{2}{*}{ Class Level } & \multirow{2}{*}{$\mathbf{N}$} & \multirow{2}{*}{$\overline{\mathbf{x}}$} & \multirow{2}{*}{ Sd } & \multicolumn{2}{|c|}{ Levene Test } & \multirow{2}{*}{$\mathbf{F}$} & \multirow{2}{*}{$\mathbf{P}$} & \multirow{2}{*}{ Sheffe } \\
\hline & & & & & Statistic & $\mathbf{p}$ & & & \\
\hline \multirow{4}{*}{ COVID-19 Fear Scale } & $1^{\text {st }}$ Year $^{(1)}$ & 244 & 14.79 & 7.14 & \multirow{4}{*}{0.30} & \multirow{4}{*}{0.83} & \multirow{4}{*}{2.30} & \multirow{4}{*}{.07} & \multirow{4}{*}{ - } \\
\hline & $2^{\text {nd }}$ Year $^{(2)}$ & 212 & 15.99 & 6.95 & & & & & \\
\hline & $3^{\text {rd }}$ Year $^{(3)}$ & 226 & 16.23 & 7.37 & & & & & \\
\hline & $4^{\text {th }}$ Year $^{(4)}$ & 78 & 16.64 & 7.02 & & & & & \\
\hline
\end{tabular}

When Table 9 is examined; As a result of examining whether there is a significant difference in the mean scores of COVID-19 fears of the students according to the class variable, no significant difference was found in the mean scores of the COVID-19 fears according to the class variable $(p>0.05)$. Because of the homogeneous distribution of group variances, Scheffe test, one of the Post-Hoc tests, was applied.

In Table 10, One-Way ANOVA results regarding the difference in COVID-19 fears according to the variable of duration of doing sports before the pandemic are given.

Table 10. One-Way ANOVA results on the difference in fears of COVID-19 according to the students' exercise duration variance before the pandemic

\begin{tabular}{|c|c|c|c|c|c|c|c|c|c|}
\hline \multirow{2}{*}{ Scale } & \multirow{2}{*}{ Exercise Period } & \multirow{2}{*}{$\mathbf{N}$} & \multirow{2}{*}{$\overline{\mathbf{x}}$} & \multirow{2}{*}{ Sd } & \multicolumn{2}{|c|}{ Levene Test } & \multirow{2}{*}{$\mathbf{F}$} & \multirow{2}{*}{$\mathbf{P}$} & \multirow{2}{*}{ Sheffe } \\
\hline & & & & & Statistic & $\mathbf{p}$ & & & \\
\hline \multirow{5}{*}{ COVID-19 Fear Scale } & $1-2$ Years $^{(1)}$ & 490 & 16.05 & 7.23 & \multirow{5}{*}{0.94} & \multirow{5}{*}{0.44} & \multirow{5}{*}{1.32} & \multirow{5}{*}{.26} & \multirow{5}{*}{-} \\
\hline & 3-4 Years ${ }^{(2)}$ & 148 & 15.82 & 7.27 & & & & & \\
\hline & 5-6 Years ${ }^{(3)}$ & 66 & 14.42 & 6.27 & & & & & \\
\hline & 7-8 Years ${ }^{(4)}$ & 34 & 14.41 & 7.74 & & & & & \\
\hline & 9 Years and Above ${ }^{(5)}$ & 22 & 14.27 & 6.34 & & & & & \\
\hline
\end{tabular}

When Table 10 is examined; As a result of examining whether there is a significant difference in the mean scores of COVID-19 fears according to the variable of the duration of doing sports before the pandemic of the students, no significant difference was found in the mean scores of the fears of COVID-19 according to the time of doing sports before the pandemic ( $p>0.05)$. Because of the homogeneous distribution of group variances, Scheffe test, one of the Post-Hoc tests, was applied. 
In Table 11, One-Way ANOVA Results regarding the difference in COVID-19 fears according to the type of sport students have done before the pandemic are given.

Table 11. One-Way ANOVA results on the difference in fears of COVID-19 according to the variable of the type of sports done by the students before the pandemic

\begin{tabular}{|c|c|c|c|c|c|c|c|c|c|}
\hline \multirow{2}{*}{ Scale } & \multirow{2}{*}{ Sports Type } & \multirow{2}{*}{$\mathbf{N}$} & \multirow{2}{*}{$\overline{\mathbf{x}}$} & \multirow{2}{*}{ Sd } & \multicolumn{2}{|c|}{ Levene Test } & \multirow{2}{*}{$\mathbf{F}$} & \multirow{2}{*}{$\mathbf{P}$} & \multirow{2}{*}{ Sheffe } \\
\hline & & & & & Statistic & $\mathbf{p}$ & & & \\
\hline \multirow{3}{*}{ COVID-19 Fear Scale } & Individual Sports ${ }^{(1)}$ & 100 & 14.58 & 6.54 & \multirow{3}{*}{1.17} & \multirow{3}{*}{0.31} & \multirow{3}{*}{1.54} & \multirow{3}{*}{.22} & \multirow{3}{*}{-} \\
\hline & Teams Sports ${ }^{(2)}$ & 238 & 15.84 & 7.17 & & & & & \\
\hline & I do not do sports ${ }^{(3)}$ & 422 & 15.96 & 7.29 & & & & & \\
\hline
\end{tabular}

When Table 11 is examined; As a result of examining whether there was a significant difference in the mean scores of COVID-19 fears according to the type of sport they did before the pandemic, no significant difference was found in the mean scores of COVID-19 fears according to the type of sport before the pandemic ( $p>0.05)$. Because of the homogeneous distribution of group variances, Scheffe test, one of the Post-Hoc tests, was applied.

\section{Discussion and Result}

In this study, it was aimed to compare according to some variables of COVID-19 fears of high school students in the pandemic process, which negatively affected the whole world. The findings of the study show that the COVID-19 fear levels of the students are only affected by the gender variable and the COVID-19 fear levels of the students participating in the study are affected by variables such as age, class, being in the school team, doing licensed sports, type of sport, duration of doing sports and being caught COVID-19 situation was found to be unaffected.

As a consequence of the study's findings, it was determined that the mean scores of female students on the "COVID-19 Fear" scale, according to the gender variable, were substantially higher than those of male students. When we the literature is considered, there are researches that that support our findings. Bakioğlu, Korkmaz, and Ercan (2020) reported that the fear of COVID-19 is significantly higher in women in their study with 960 adult individuals. Gencer (2020) reported that women's fear of coronavirus is higher than men. Arpacioglu et al. (2021) reported that the mean scores of women on the COVID-19 scale were higher than those of men. Studies that do not show parallelism with our research are; According to Duman (2020), it was reported that there was no significant difference in COVID-19 fear levels according to the gender variable. Arikan (2021) reported that there was no significant difference in the mean scores of female and male participants from the COVID-19 fear scale according to the gender variance. 
In our research, the mean scores of the students on the COVID-19 scale according to the age variable revealed that there was no significant difference in fear of COVID-19 between age groups. Given that the COVID-19 epidemic primarily affects older people, it is hypothesized that the fact that our study sample consisted of high school students and younger people were less afflicted by this disease may have contributed to this finding. Ciftci and Demir (2020) found that the COVID-19 fear scores of the participants did not differ depending on their age during the pandemic process. Arıkan (2021) reported that there was no significant difference between the average scores of the participants from the COVID-19 fear scale according to the age variable. In these studies, researchers have reached findings that support our study. However, according to Gencer (2020), there were substantial disparities in the scores of the groups based on the age variable. The group with the smallest average age was observed to have the highest fear of COVID-19, and as the participants' ages increased, their fear of COVID-19 reduced. This study shows no parallelism with ours.

In our study, there was no significant difference in the mean scores of the students from the COVID-19 scale according to the class variable across the class groups in terms of dread of the COVID-19. There are no studies in the literature that show comparable or different findings depending on the class variable.

In our analysis, we discovered that the average score of the students on the COVID-19 scale according to the variable of being on the school team before to the pandemic, and the status of being on the school team prior to the pandemic, did not produce a significant difference in terms of fear of COVID-19. In the literature, there were no studies in which similar and different results were obtained according to the variable of being in the school team before the pandemic.

In our study, we discovered that the average score of the students on the COVID-19 scale according to the licensed sporting variable before to the pandemic, and the licensed sports status prior to the pandemic, did not produce a significant difference in terms of fear of COVID-19. In the literature, no studies were found in which similar and different results were obtained according to the variable of doing licensed sports before the pandemic.

In our study, we observed that the average score of the students on the COVID-19 scale based on the type of sport they participated in before to the pandemic did not produce a significant difference in terms of fear of COVID-19 based on the type of sport they participated in prior to the pandemic. There are studies in the body of the literature that back up our findings. Çiftçi and Demir (2020) found that the level of fear of the participants due to COVID-19 is moderate and that it can be interpreted as that the football players who play team sports do not have too many mental problems due to COVID-19. Arıkan (2021) reported that they found that the difference between the average COVID-19 scale scores of the candidates who did team sports and individual sports was not statistically significant.

In our study, there was no significant difference in the mean scores of the students on the COVID-19 scale based on the variable of the length of performing sports, and the fear of COVID-19 between the groups of time to do sports. There was no research in the literature that had comparable or dissimilar outcomes based on the variable of length of doing sports. 
In our research, we revealed that the average score of the students on the COVID-19 scale based on the variable of capturing COVID-19 did not result in a significant difference in terms of fear of COVID-19 based on the scenario of catching COVID-19. There are studies in the body of the literature that support our research results. Bakioğlu, Korkmaz, and Ercan (2020) reported that the level of fear of COVID-19 does not cause a significant difference according to the status of himself or one of his relatives contracting the disease. The findings of this study show parallelism with the results of our study. According to Arkan (2021), the difference in average COVID-19 scale scores between individuals with a history of COVID-19 and those without a history of COVID-19 was not statistically significant.

As a consequence, high school students' fear of COVID-19 is modest, and according to the study's findings, several elements play a role (age, class, being in the school team, licensed sports, type of sports, duration of sports and catching COVID-19) It was discovered that there were no significant variations in COVID-19 concerns. The explanation for this is assumed to be because COVID-19 illness primarily affects middle-aged and older persons, and hence there is no substantial difference in COVID-19 fear levels among young people depending on the factors tested. In our study, it was seen that the only variable that significantly affected the fear of COVID-19 was gender. Based on this finding, it was discovered that female students' COVID-19 fear levels were much greater than male students. This is supposed to be because female students have a more emotional and vulnerable structure.

\section{Reference}

Ahorsu, D. K., Lin, C.-Y., Imani, V., Saffari, M., Griffiths, M. D., \& Pakpour, A. H. (2020). The Fear of COVID-19 Scale: Development and initial validation. International Journal of Mental Health and Addiction. https://doi.org/10.1007/s11469-020-00270-8

Aktuğ, Z. B., İri, R., \& Aktuğ Demir, N. (2020). COVID-19 immune system and exercise. Journal of Human Sciences, 17(2), 513-520. https://doi.org/10.14687/ jhs.v17i2.6005

Arıkan, G., Gökhan, İ., \& İnce, U. (2021). Examination of COVID-19 Fear Levels of Physical Education and Sports School Student Candidates during the Pandemic Process. Journal of ROL Sport Sciences, 2(1).

Arpacigolu, M. S., Baltaci, Z., \& Unubol, B. (2021). Burnout, fear of COVID, depression, occupational satisfaction levels and related factors in healthcare workers in the COVID-19 pandemic. Cukurova Med J, 46(1), 88-100. https://doi.org/10.17826/cumj.785609

Bakioğlu, F., Korkmaz, O., \& Ercan, H. (2020). Fear of COVID-19 and positivity: Mediating role of intolerance of uncertainty, depression, anxiety, and stress. International Journal of Mental Health and Addiction, 19, 2369-2382. https://doi.org/10.1007/s11469-020-00331-y

Brown, E., Gray, R., Lo Monaco, S., O’Donoghue, B., Nelson, B., Thompson, A., ... McGorry, P. (2020). The potential impact of COVID-19 on psychosis: A rapid review of contemporary epidemic and pandemic research. Schizophr Res., 222, 79-87. https://doi.org/10.1016/j.schres. 2020.05.005 


\section{Macrothink}

Cifci, F., \& Demir, A., (2020). Investigation of COVID-19 Fear and Anxiety Levels of Turkish Professional Football Players in the COVID-19 Pandemic. Journal of Sports and Recreation Research, 2(1), 26-38.

Duman N. (2020). Fear of COVID-19 and Intolerance of Uncertainty among University Students. The Journal of Social Science, 4(8), 426-437. https://doi.org/10.30520/tjsosci. 748404

Gencer, N. (2020). People's Fear of Coronavirus (Kovid-19) During the Pandemic Process: The Case of Çorum. USBAD Journal of International Social Sciences Academy, 2(4), 1153-1173.

Karasar, N. (2015). Scientific research method. Ankara: Nobel Publications.

Lai, C.-C., Shih, T.-P., Ko, W.-C., Tang, H.-J., \& Hsueh, P.-R. (2020). Severe acute respiratory syndrome coronavirus 2 (SARS-CoV-2) and coronavirus disease-2019 (COVID-19): The epidemic and the challenges. International Journal of Antimicrobial Agents, 55(3), 105924. https://doi.org/10.1016/j.ijantimicag.2020.105924

Mamun, M. A., \& Griffiths, M. D. (2020). First COVID-19 suicide case in Bangladesh due to fear of COVID-19 and xenophobia: Possible suicide prevention strategies. Asian Journal of Psychiatry, 51(102073), 102073. https://doi.org/10.1016/j.ajp.2020.102073

Pakpour, A., \& Griffiths, M. D. (2020). The fear of COVID-19 and its role in preventive behaviors. Journal of Concurrent Disorders, 2(1), 58-63. https://doi.org/10.54127/WCIC8036

Reardon, C. L., Hainline, B., Aron, C. M., Baron, D., Baum, A. L., ... Currie, A. (2019). Mental health in elite athletes: International Olympic Committee consensus statement. $\mathrm{Br} . J$. Sports Med., 53(11), 667-699. https://doi.org/10.1136/bjsports2019-100715

Şahinler, Y., Ulukan, M., \& Ulukan, H. (2020). Examination of Aggression Levels of Sports Sciences Faculty Students Doing Physical Activity in the COVID-19 Process. Mediterranean Journal of Sport Sciences, 3(1), 171-184.

Schimmenti, A., Billieux, J., \& Starcevic, V. (2020). The four horsemen of fear: An integrated model of understanding fear experiences during the COVID-19 pandemic. Clinical Neuropsychiatry, 17(2), 41-45.

Wang, C., Pan, R., Wan, X., Tan, Y., Xu, L., Ho, C. S., \& Ho, R. C. (2020). Immediate psychological responses and associated factors during the initial stage of the 2019 coronavirus disease (COVID-19) epidemic among the general population in China. International Journal of Environmental Research and Public Health, 17(5), 1729. https://doi.org/10.3390/ ijerph17051729

WHO (World Health Organization). (2020). Clinical management of severe acute respiratory infection (SARI) when COVID-19 disease is suspected: Interim guidance. https://doi.org/ 10.15557/PiMR.2020.0003 


\section{Macrothink}

Journal of Educational Issues ISSN 2377-2263

2021, Vol. 7, No. 3, Special Issue

WHO (World Health Organization). (2021). Coronavirus disease (COVID-19) pandemic. WHO Coronavirus (COVID-19) Dashboard.

\section{Copyright Disclaimer}

Copyright for this article is retained by the author(s), with first publication rights granted to the journal.

This is an open-access article distributed under the terms and conditions of the Creative Commons Attribution license (http://creativecommons.org/licenses/by/3.0/). 